\title{
Community junior sport sponsorship: an online experiment assessing children's responses to unhealthy food $v$. pro-health sponsorship options
}

\author{
Helen Dixon ${ }^{1, *}$, Maree Scully ${ }^{1}$, Melanie Wakefield ${ }^{1}$, Bridget Kelly $^{2}$ and Simone Pettigrew ${ }^{3}$ \\ ${ }^{1}$ Centre for Behavioural Research in Cancer, Cancer Council Victoria, 615 St Kilda Road, Melbourne, VIC 3004, \\ Australia: ${ }^{2}$ Early Start Research Institute, School of Health and Society, University of Wollongong, Wollongong, \\ New South Wales, Australia: ${ }^{3}$ School of Psychology and Speech Pathology, Curtin University, Bentley, Western \\ Australia, Australia
}

Submitted 20 December 2016: Final revision received 24 0ctober 2017: Accepted 2 November 2017: First published online 6 December 2017

\begin{abstract}
Objective: To explore children's responses to sponsorship of community junior sport by unhealthy food brands and investigate the utility of alternative, pro-health sponsorship options.

Design: Between-subjects experiment, with four sponsorship conditions: A, nonfood branding (control); B, unhealthy food branding; C, healthier food branding; $\mathrm{D}$, obesity prevention campaign branding.

Setting: Online experiment conducted in schools. Participants were shown a junior sports pack for their favourite sport that contained merchandise with branding representing their assigned sponsorship condition. Participants viewed and rated the sports pack, completed a distractor task, then completed questions assessing brand awareness, brand attitudes and preference for food sponsors' products.

Subjects: Students in grades 1 to 3 (aged 5-10 years; $n$ 1124) from schools in metropolitan Melbourne, Australia.

Results: Compared with the control condition, there were no significant effects of unhealthy food branding on awareness of, attitudes towards or preference for these brands. Exposure to healthier food branding prompted a significant increase in the proportion of children aware of these brands, but did not impact attitudes towards or preference for these brands. Exposure to either healthier food branding or obesity prevention campaign branding prompted a significant reduction in the proportion of children showing a preference for unhealthy food sponsor products. Conclusions: The sponsorship of children's sport by healthier food brands may promote awareness of these brands and healthier sponsorship branding may reduce preferences for some unhealthy food products. Establishing and implementing healthy sponsor criteria in sports clubs could forge healthier sponsorship arrangements and help phase out unhealthy food and beverage sponsors.
\end{abstract}

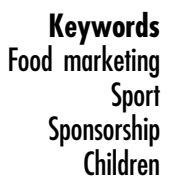

Childhood overweight and obesity is a significant public health problem globally ${ }^{(1)}$, including in Australia where one in four children is affected ${ }^{(2)}$. These children have increased risk of poorer reported general health, lower psychological functioning and specific health disorders ${ }^{(3)}$, and are more likely to become overweight adults ${ }^{(4)}$ and experience associated chronic diseases such as type 2 diabetes, heart disease and some cancers ${ }^{(5)}$. Food marketing has been implicated in the obesity epidemic for predominantly promoting energy-dense and nutrient-poor ('unhealthy') foods and beverages, directly influencing children's food preferences, purchasing behaviour and consumption patterns ${ }^{(6)}$. To date, much of the research examining effects of food marketing on children has focused on television food advertising ${ }^{(7)}$. However, concerns have arisen about the role that unhealthy food sponsorship of children's sport may play in promoting unhealthy eating to large numbers of children ${ }^{(8)}$.

Participation in sport enables children to be physically active, which delivers a range of health benefits including helping them achieve or maintain a healthy weight ${ }^{(9,10)}$. In Australia, the majority of children participate in organised 
sport (60\%), spending an average of $5 \mathrm{~h}$ per fortnight engaged in these types of activities ${ }^{(11)}$. These high participation rates make organised sport an attractive setting for commercial marketers to reach children as well as for nutrition promotion efforts ${ }^{(12)}$.

While food advertising to children via mass-media broadcasting is prohibited or restricted in some international jurisdictions, food marketing in children's sport settings is not typically captured by such regulations ${ }^{(13)}$. In Australia there are relatively few restrictions concerning food marketing to children in any form ${ }^{(13)}$, and corporate sponsorship of elite and community sport is commonplace $^{(14,15)}$. Such sponsorship often involves companies promoting unhealthy foods and beverages, alcohol and gambling products ${ }^{(15-17)}$. This is also the case in neighbouring New Zealand ${ }^{(18,19)}$, where a study of sponsors for the most popular sports among young people (aged 5-17 years) found that sponsorship targeting junior players and teams was more likely to be for unhealthy foods than other types of products ${ }^{(19)}$. A recent Australian study found that the majority of food and beverage company sponsors of children's sport development programmes were companies associated with unhealthy products ${ }^{(16)}$. Unhealthy sponsor brands are promoted using various strategies including logo placement on website home pages, naming rights (i.e. incorporation of a company's brand name into the name of a team, event or stadium), logos on sport uniforms and branded participant packs, and gift vouchers for sponsor products ${ }^{(14,16)}$.

The 'mere exposure' perspective predicts that increased brand exposure leads to increased brand liking and preference; a higher evaluation of a product can occur without conscious processing of the advertising ${ }^{(20)}$. Evidence of mere-exposure effects in relation to sponsorship has been reported in the literature ${ }^{(21)}$. For example, a UK study found that frequency of attending sporting events predicted purchase intentions for sponsors' products ${ }^{(22)}$. The level of investment in sport sponsorship (estimated to be $\$$ AU 774 million in Australia annually ${ }^{(23)}$ ) suggests that the brand exposure this type of marketing provides is highly valued by companies as an effective way to reach and influence consumers.

Despite the pervasiveness of sport sponsorship by companies promoting unhealthy foods and beverages in Australia, many members of the public do not support this form of marketing activity ${ }^{(24)}$ and most adults would support restrictions on sponsorship of children's sporting activities by unhealthy food brands ${ }^{(25-27)}$. However, concerns about the financial implications of unhealthy food sponsorship restrictions for community sports clubs, as well as a perception among many parents that children are more influenced by sponsors of elite sport than their own local club, are barriers to achieving policy change ${ }^{(27)}$.

Previous research examining effects of elite sport sponsorship elucidates potential impacts of sponsorship of children's community sport. Sport sponsorship provides a powerful opportunity to strengthen brand attachment and brand image and to enhance public perceptions of good corporate citizenship ${ }^{(28-30)}$. 'In effect, the sponsor, in agreeing to sponsor a particular event or activity, is purchasing the rights to associate with the profile and image of the event and to exploit this association for commercial ends $^{\text {,(31) }}$ (p. 329). Exposure to sports sponsorship can transfer positive image values of being healthy, young and energetic to sponsor brands ${ }^{(31)}$. Using sport sponsorship to create a 'health halo' around particular brands is arguably problematic when the sponsor brand represents an unhealthy product. In the present climate of an obesity epidemic, in which the proliferation of energy-dense and nutrient-poor food is implicated, sport sponsorship provides an opportunity for marketers to team up unhealthy foods with fitness, vitality and excitement. Sponsorship may be an especially persuasive marketing strategy because it engages the consumer differently from other forms of promotion. Sport sponsorship can bestow the benefit of an activity with which the consumer may have an intense emotional relationship ${ }^{(32)}$, helping to create emotional bonding with the brand. Sponsorship can increase brand awareness, modify brand image and increase intentions to purchase sponsor products ${ }^{(28,33)}$. Consumer studies relating to tobacco and alcohol sponsorship have repeatedly demonstrated that sponsorship has an impact on children's product recall and productrelated attitudes and behavioural intentions ${ }^{(33,34)}$. Studies with Australian children found that three-quarters of children show implicit recall of sponsors associated with elite sporting teams ${ }^{(35,36)}$.

Previous studies examining sponsorship in children's sport settings have been largely descriptive or crosssectional and have focused on documenting the extent of this marketing practice as well as children's and adults' perceptions of it. Kelly et al. ${ }^{(37)}$ surveyed about 100 children aged 10-14 years at sports clubs and found that most (68\%) could recall sponsors of their club and had received a voucher $(86 \%)$ or certificate $(76 \%)$ from a food or beverage company to reward sport performance. Approximately one-third of children reported liking the company more after receiving these rewards. The pre-teen children in their sample were more likely than older children to report: thinking about sponsors when buying foods or drinks; that they like returning the favour to sponsors by buying their products; and that sponsors were cool. These age-related differences align with research on televised advertising, which suggests that younger children are less aware of the persuasive intent of advertising and may be especially receptive to its influence ${ }^{(38)}$. In general, children tend to be less aware of advertising tactics than adults and are more susceptible to persua$\operatorname{sion}^{(39,40)}$. They are also an important target group for marketers, as they are beginning to develop loyalty to particular brands. For marketers, the longevity and success of a brand are dependent on building brand loyalty by 
establishing psychological and emotional connections between consumers and brands ${ }^{(41)}$. As junior sports sponsorship may offer a powerful promotional route for building brand loyalty, there is a need for experimental research investigating how sponsorship of junior sport impacts children.

The present experimental study aimed to assess children's reactions to junior sport sponsorship by unhealthy food brands and to explore the utility of alternative sponsorship scenarios, namely (i) healthier food brand sponsorship, (ii) obesity prevention campaign sponsorship and (iii) non-food sponsorship (e.g. bank, airline or telecommunications brand), directed at reconfiguring the junior sport sponsorship environment to encourage healthier food preferences. These alternative scenarios are based on recognition that most children's community sport in Australia is dependent on some form of sponsorship income to be viable ${ }^{(42)}$. Any policy action to restrict unhealthy food promotions and branding in these settings must consider the need for replacement funding sources. If these alternative funding sources can promote healthy rather than unhealthy eating, this could be beneficial.

We hypothesise that unhealthy food branding will promote higher awareness of $\left(\mathrm{H} 1_{\mathrm{a}}\right)$, preference for (based on a hypothetical food choice task; $\mathrm{H}_{\mathrm{b}}$ ) and more favourable attitudes towards $\left(\mathrm{H} 1_{\mathrm{c}}\right)$ unhealthy food sponsor products compared with a control condition (non-food branding). Similarly, we expect that healthier food branding will promote higher awareness of $\left(\mathrm{H} 22_{\mathrm{a}}\right)$, preference for $\left(\mathrm{H} 2_{\mathrm{b}}\right)$ and more favourable attitudes towards $\left(\mathrm{H} 2_{\mathrm{C}}\right)$ healthier food sponsor products relative to non-food branding. In addition, we test whether obesity prevention campaign branding promotes increased preference for healthier foods $\left(\mathrm{RQ} 1_{\mathrm{a}}\right)$, more favourable attitudes towards healthier food sponsor products $\left(\mathrm{RQ} 1_{\mathrm{b}}\right)$ and less favourable attitudes towards unhealthy food sponsor products $\left(\mathrm{RQ} 1_{\mathrm{c}}\right)$, compared with the control condition.

\section{Methods}

\section{Design and procedure}

A between-subjects web-based experiment was conducted with children randomly assigned to one of four junior sport sponsorship conditions: A, non-food branding (control); B, unhealthy food branding; C, healthier food branding; or $\mathrm{D}$, obesity prevention campaign branding. Within conditions, participants were further randomised to one of three product categories (breakfast cereal, takeaway food or non-alcoholic beverage). Participants viewed an image of a pack of merchandise for their favourite sport that featured branding reflecting their assigned sponsorship condition. To separate sponsorship exposure from assessing sponsorship impact, participants then completed demographic questions and a short distractor task before answering a series of questions assessing their brand awareness, brand attitudes towards and preference for food sponsor products in response to the intervention. Finally, participants reported their usual frequency of consuming unhealthy and healthier food sponsor products; these items were asked last to avoid priming responses to the intervention.

Participants were grade 1 to 3 students (age range: 5-10 years) recruited from a random sample of primary schools located in areas of varying socio-economic status $(\mathrm{SES})^{(43)}$ across metropolitan Melbourne, Australia. Approval to conduct the study was obtained from the Human Research Ethics Committee of Cancer Council Victoria, relevant state education authorities and principals of participating schools. Students for whom parent/carer consent was received completed the online survey using individual tablet computers in small class groups under the supervision of trained research staff. To overcome any reading limitations that children of this age may have, students were provided with headphones, so they could hear the questions being read out. The study was initially described to parents/carers and students as an investigation of their views on different food products to avoid biasing the results. On completion of the survey, students were fully debriefed on the study aims and received an A4 poster of the Healthy Eating Pyramid (http://www. nutritionaustralia.org/national/resource/healthy-eatingpyramid). A letter detailing the specific focus and objectives of the study and a copy of the Healthy Eating for Children brochure developed by the Australian Government (http://www.eatforhealth.gov.au/guidelines) was sent home to parents/carers.

\section{Intervention: sponsor branded sports packs}

Children's exposure to the intervention was designed to simulate online the process of enrolling in a local sports club and receiving branded merchandise at the start of the season. To engage children with merchandise for a sport they were personally interested in, students were initially asked to nominate which of six sports popular with Australian children (basketball, cricket, Australian Rules football (AFL), netball, soccer, tennis) they would choose if they could join a local sports club. They were then shown an image of a pack of youth-oriented merchandise for that sport that was repeatedly branded with a logo reflecting their assigned sponsorship condition. Each sports pack included a backpack, T-shirt, water bottle, hat, sticker book and ball (see Fig. 1 for examples). Students were asked to look carefully at what was in the sports pack and then rate how much they liked it and how they would feel if they could keep it. The length of time students spent viewing the sports pack on screen was recorded by the survey software.

\section{Measures}

In the absence of suitable validated scales in the literature, age-appropriate measures were adapted from previous research assessing young children's responses to food 
A

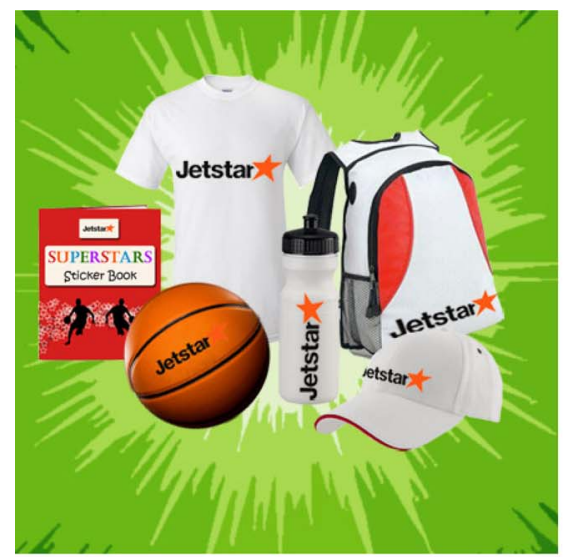

C

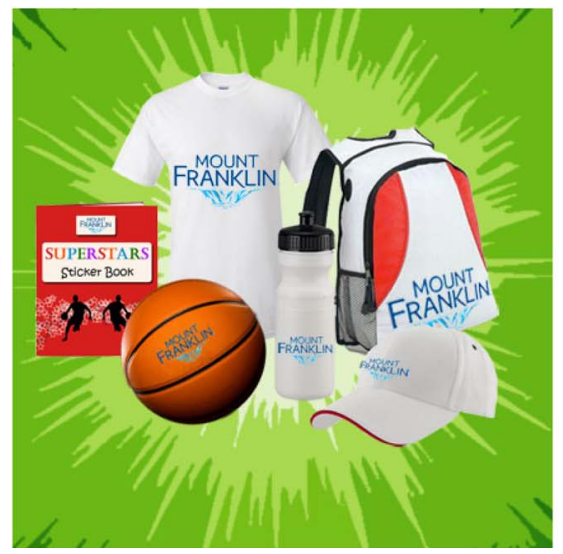

B

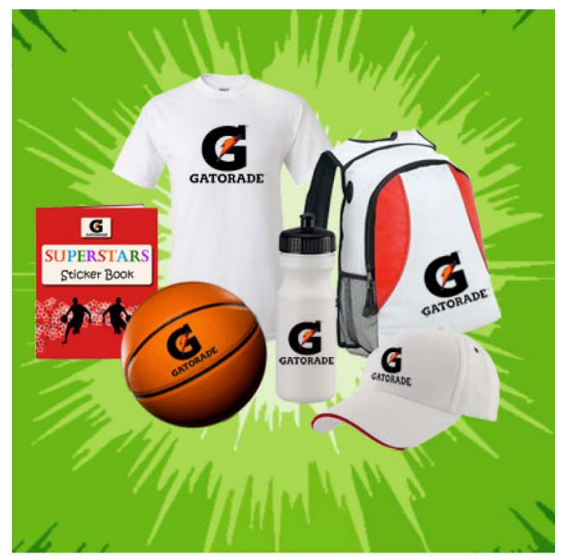

D

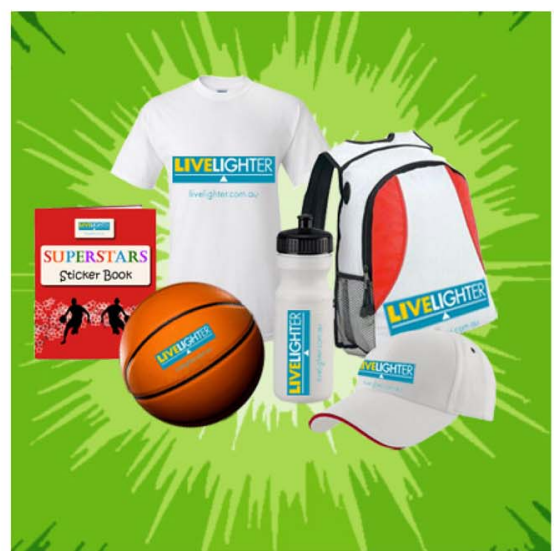

Fig. 1 (colour online) Examples of branded merchandise included in the sports packs by sponsorship condition: A, non-food branding; $\mathrm{B}$, unhealthy food branding; $\mathrm{C}$, healthier food branding; $\mathrm{D}$, obesity prevention campaign branding

promotions $^{(44-46)}$ and consumer responses to sponsorship $^{(47)}$ in order to assess the following outcomes.

\section{Top-of-mind brand awareness}

Participants were asked to indicate which brand they thought of first when prompted to think of (i) a breakfast cereal, (ii) takeaway food or (iii) drinks you can buy (depending on their assigned product category). This measure was adapted from Jalleh et $a l .{ }^{(47)}$ to focus specifically on top-of-mind brand awareness (rather than brand awareness generally). It was also simplified to include a list of pre-coded options, with logos displayed next to brand names to aid participant recognition of each brand option. Response options were presented in random order and included the unhealthy and healthier food sponsor brands featured in conditions B and C, four distractor brands (chosen based on their popularity with young children and/or similarity to the unhealthy or healthier sponsor brand featured) and an 'other' option.

\section{Brand preferences}

Participants were shown images of two unhealthy and two healthier branded products from their assigned food product category (including one product from the respective food sponsors featured in conditions B and C) and asked to choose which they would most like to have. The unhealthy food brands were for foods that contain more kilojoules and higher levels of fat, sugar and/or sodium per $100 \mathrm{~g} / 100 \mathrm{ml}$ than the healthier comparison brand. This measure was based on a product preference question used in previous experimental studies with children of primary-school age, which asked participants to choose between an unhealthy food product and a healthier comparison food product ${ }^{(46,48)}$. For the present study, participants were asked to choose one product from four options (two unhealthy and two healthier) to enable assessment of whether the experimental manipulation affected preference for sponsor products, as well as overall preference for healthier foods.

Participants assigned the breakfast cereal product category were given the choice of Nutri-Grain (unhealthy sponsor brand), Milo cereal (unhealthy non-sponsor brand), Weet-Bix (healthier sponsor brand) and Cheerios (healthier non-sponsor brand). Participants assigned to the takeaway food category were given the choice of McDonald's (unhealthy sponsor brand), KFC (unhealthy 
non-sponsor brand), Sushi Sushi (healthier sponsor brand) or Subway (healthier non-sponsor brand). Participants assigned to the non-alcoholic beverage product category were given the choice of Gatorade (unhealthy sponsor brand), Powerade (unhealthy non-sponsor brand), Mount Franklin (healthier sponsor brand) and Cool Ridge spring water (healthier non-sponsor brand). All the products featured as sponsor and non-sponsor brands within a given product category (e.g. cereal, takeaway food, nonalcoholic beverage) were chosen because they are prominent brands in the Australian marketplace. The brands featured as sponsors have previously used sport sponsorship to market their products in Australia. The non-sponsor brands represented a similar brand to their corresponding sponsor brand in terms of product type, healthfulness and brand prominence (e.g. Gatorade $v$. Powerade).

\section{Brand attitudes}

For each food sponsor brand in their assigned product category, participants were asked to indicate: 'How much do you like (product)?'; 'How do you think (product) would taste?'; 'How healthy do you think (product) is?'; 'Would you ask your parents for (product)?'; 'How would you feel if your parents bought (product) for you?'. These brand attitude measures were based on questions from McAlister and Cornwell ${ }^{(44)}$ (likeability and anticipated taste), Levin and Levin ${ }^{(45)}$ (perceived healthiness and feel if parent bought product) and Dixon et al. ${ }^{(46)}$ (ask parent for product). As per Levin and Levin ${ }^{(45)}$, responses were recorded on 5-point pictorial scales ranging from 1 (smile) to 5 (frown). Each question was displayed on a separate screen, with an image of the product being rated shown at the top of each question. The order in which the unhealthy and healthier food sponsor brands were rated was counterbalanced across participants.

\section{Demographics}

Participants recorded their sex, age and school grade level. A measure of SES was determined according to the SocioEconomic Index for Areas Index of Relative SocioEconomic Disadvantage based on participant's school postal code. Using the state deciles to create quintiles, participants were categorised into the following SES groups: low (first and second quintiles); medium (third and fourth quintiles); high (fifth quintile).

\section{Usual consumption of sponsor products}

Participants were also asked about their frequency of consuming Nutri-Grain and Weet-Bix (breakfast cereal product category), McDonald's and 'sushi from a takeaway food place' (takeaway food product category), or Gatorade and 'water that you buy in a bottle' (nonalcoholic beverage product category). Response options included 'every day', 'a few times a week', 'a few times a month', 'a few times a year' and 'never'.

\section{Statistical analysis}

Data were analysed using the statistical software package Stata/MP version 14.2. Preliminary analyses were performed to check that random assignment yielded equivalent demographic groups. For analysis purposes, the brand attitude items were reverse coded so that higher scores reflected more favourable brand attitudes. Logistic regression was used to test for differences by sponsorship condition in top-of-mind brand awareness and brand preferences for the (i) unhealthy and (ii) healthier sponsor products and preference for healthier brands more generally. Linear regression was used to test whether participant ratings of the (i) unhealthy and (ii) healthier sponsor products varied by sponsorship condition. All models used the non-food branding (control) condition as the reference group. Initially each model was run with the interaction between sponsorship condition and product category included. As none of the interactions were significant, sponsorship effects were interpreted as equivalent across product categories. However, product category was retained as a covariate in the final models. We also ran the models controlling for usual consumption of sponsor products; as comparable effects of the sponsorship manipulation were observed, usual consumption was not included as a covariate in the final models.

\section{Results}

A total of 1124 children (estimated student response rate $=44 \%$ ) across twelve schools (school response rate $=10 \%$ ) participated in the study. The demographic profile of the sample is summarised in Table 1. None of the individual factors measured (sex, age, school grade level, SES, and frequency of consuming unhealthy and healthier food sponsor products) were found to be unevenly distributed across sponsorship conditions, indicating successful randomisation.

\section{Manipulation checks}

On average, children spent $18 \mathrm{~s}$ viewing their assigned sports pack on screen, with comparable intervention exposure times across conditions $\left(F_{(3,1120)}=0 \cdot 21\right.$, $P=0.892)$. Overall, children liked the sports pack (mean 4.28 (SD 0.93)) and would feel happy if they could keep it (mean 4.43 (SD 0.82)). There were no significant differences in children's ratings of how much they liked the sports pack $\left(F_{(3,1120)}=1.32, \quad P=0.268\right)$ and how they would feel if they could keep it $\left(F_{(3,1120)}=0 \cdot 31, P=0 \cdot 819\right)$ based on the type of branding (i.e. non-food, unhealthy, healthier, obesity prevention campaign) featured on the merchandise included.

Among the non-food branding sub-sample (control condition), the healthier food sponsor product was rated as significantly more healthy than the unhealthy food sponsor product (mean 4.06 v. 2.61; $t_{(288)}=15 \cdot 15$, 
Table 1 Demographic characteristics of participants by sponsorship condition: students in grades 1 to 3 (aged $5-10$ years; $n$ 1124) from schools in metropolitan Melbourne, Australia, May-August 2016

\begin{tabular}{|c|c|c|c|c|c|c|}
\hline & \multirow[b]{2}{*}{$\begin{array}{c}\text { Total } \\
(n 1124)\end{array}$} & \multicolumn{4}{|c|}{ Sponsorship condition } & \multirow[b]{3}{*}{$P$ value } \\
\hline & & $\begin{array}{c}\text { Non-food } \\
\text { branding (control) } \\
(n 289)\end{array}$ & $\begin{array}{l}\text { Unhealthy food } \\
\text { branding } \\
(n 273)\end{array}$ & $\begin{array}{l}\text { Healthier food } \\
\text { branding } \\
\text { ( } n 280)\end{array}$ & $\begin{array}{l}\text { Obesity prevention } \\
\text { campaign branding } \\
(n \text { 282) }\end{array}$ & \\
\hline & $\%$ & $\%$ & $\%$ & $\%$ & $\%$ & \\
\hline Sex & & & & & & 0.335 \\
\hline Male & $51 \cdot 3$ & $48 \cdot 8$ & $56 \cdot 0$ & $50 \cdot 4$ & $50 \cdot 4$ & \\
\hline Female & $48 \cdot 7$ & $51 \cdot 2$ & $44 \cdot 0$ & $49 \cdot 6$ & $49 \cdot 6$ & \\
\hline Age (years) & & & & & & 0.977 \\
\hline Mean & $7 \cdot 2$ & $7 \cdot 2$ & $7 \cdot 2$ & $7 \cdot 2$ & $7 \cdot 2$ & \\
\hline SD & 0.9 & 0.9 & 0.9 & 1.0 & 0.9 & \\
\hline School grade level & & & & & & 0.913 \\
\hline 1 & 38.5 & 37.4 & 41.4 & 37.5 & 37.9 & \\
\hline 2 & 38.3 & 37.7 & $37 \cdot 0$ & 38.6 & $40 \cdot 1$ & \\
\hline 3 & $23 \cdot 1$ & 24.9 & $21 \cdot 6$ & 23.9 & $22 \cdot 0$ & \\
\hline Socio-economic status & & & & & & 0.611 \\
\hline Low & 7.9 & $6 \cdot 9$ & $7 \cdot 7$ & 7.5 & $9 \cdot 6$ & \\
\hline Medium & $48 \cdot 3$ & $45 \cdot 7$ & $47 \cdot 6$ & $52 \cdot 1$ & $47 \cdot 9$ & \\
\hline High & $43 \cdot 8$ & 47.4 & 44.7 & $40 \cdot 4$ & $42 \cdot 6$ & \\
\hline $\begin{array}{l}\text { Frequency of consuming unhealthy } \\
\text { food sponsor products }\end{array}$ & & & & & & 0.291 \\
\hline At least a few times a month & $47 \cdot 7$ & $50 \cdot 2$ & $50 \cdot 9$ & $45 \cdot 4$ & 44.3 & \\
\hline A few times a year/never & $52 \cdot 3$ & 49.8 & $49 \cdot 1$ & 54.6 & 55.7 & \\
\hline $\begin{array}{l}\text { Frequency of consuming healthier } \\
\text { food sponsor products }\end{array}$ & & & & & & 0.458 \\
\hline At least a few times a month & $59 \cdot 8$ & $62 \cdot 6$ & $61 \cdot 5$ & $57 \cdot 1$ & $57 \cdot 8$ & \\
\hline A few times a year/never & $40 \cdot 2$ & 37.4 & 38.5 & $42 \cdot 9$ & $42 \cdot 2$ & \\
\hline
\end{tabular}

Percentages may not sum to $100 \%$ due to rounding.

$P<0 \cdot 001)$, suggesting that children's perception of the healthiness of the products aligned with the products' actual nutritional profiles.

\section{Top-of-mind brand awareness}

As shown in Fig. 2, children exposed to unhealthy food branding did not have higher awareness of the unhealthy food sponsor product than those exposed to non-food branding, thus rejecting $\mathrm{H}_{\mathrm{a}}(24 \cdot 2 \mathrm{v} \cdot 28 \cdot 0 \%$; adjusted $\mathrm{OR}=$ $0.83,95 \%$ CI $0.55,1 \cdot 26, P=0.387)$. However, as hypothesised $\left(\mathrm{H}_{2}\right)$, awareness of the healthier food sponsor product was significantly higher among children exposed to healthier food branding compared with non-food branding (21.1 $v$. $13.5 \%$; adjusted $\mathrm{OR}=1.72,95 \%$ CI $1.10,2.69, P=0.017$ ). Also, children in the healthier food branding condition had lower awareness of the unhealthy food sponsor product than those in the non-food branding condition $(21 \cdot 1 v$. $28.0 \%$; adjusted $\mathrm{OR}=0.65,95 \%$ CI $0.42,0.99, P=0.043$ ).

\section{Brand preferences}

Figure 3 displays the proportion of children in each condition who indicated a preference for the unhealthy food sponsor branded product and the healthier food sponsor branded product, respectively. $\mathrm{H}_{\mathrm{b}}$ and $\mathrm{H} 2_{\mathrm{b}}$ were not supported: children exposed to unhealthy food branding were no more likely to choose the unhealthy food sponsor product than children exposed to non-food branding

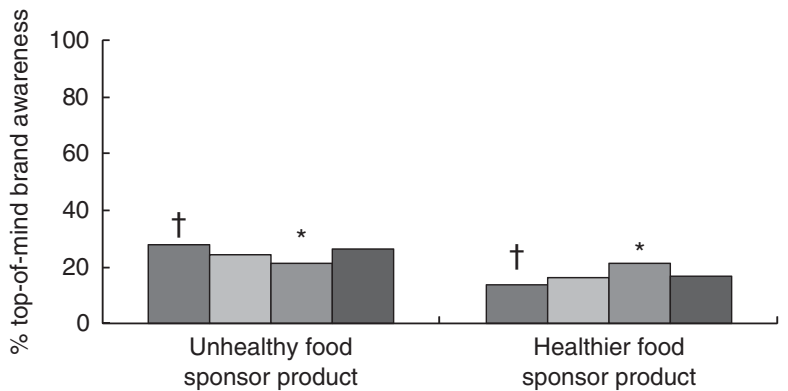

Fig. 2 Proportion with top-of-mind brand awareness for unhealthy food sponsor products and healthier food sponsor products by sponsorship condition ( $\square$, non-food branding; $\square$, unhealthy food branding; $\square$, healthier food branding; $\square$, obesity prevention campaign branding) among students in grades 1 to 3 (aged $5-10$ years; $n$ 1124) from schools in metropolitan Melbourne, Australia, May-August 2016. ${ }^{\star} P<0.05 ;{ }^{* *} P<0.01$; treference category for logistic regression analyses

(33.0 v. 40.1\%; adjusted $\mathrm{OR}=0.74,95 \%$ CI $0.51,1.06$, $P=0.096)$; children exposed to healthier food branding were no more likely to choose the healthier food sponsor product than children exposed to non-food branding (25.4 v. $21 \cdot 8 \%$; adjusted $\mathrm{OR}=1 \cdot 22,95 \%$ CI $0.82,1 \cdot 81$, $P=0.320)$. However, there was of evidence of reduced preference for the unhealthy food sponsor brands among children exposed to the healthier food brands $(31.4 v$. $40 \cdot 1 \%$; adjusted $\mathrm{OR}=0.67,95 \%$ CI $0.46,0.96, P=0.027$ ) or obesity prevention campaign brands $(29 \cdot 4 v .40 \cdot 1 \%$; 
adjusted $\mathrm{OR}=0 \cdot 60,95 \% \mathrm{CI} 0 \cdot 42,0 \cdot 86, P=0 \cdot 006)$ compared with the non-food brand condition.

\section{Overall preference for bealthier v. unbealtby food}

In addressing $\mathrm{RQ1} 1_{\mathrm{a}}$, it was observed that the likelihood of children indicating a preference for either one of the healthier foods was not significantly higher among those exposed to obesity prevention campaign branding compared with non-food branding (42.6 v. 37.7\%; adjusted $\mathrm{OR}=1 \cdot 24,95 \%$ CI $0.88,1 \cdot 75, P=0.215)$. There was also no evidence that children's overall propensity to choose a healthier product was affected by healthier food branding (38.6 v. 37.7\%; adjusted $\mathrm{OR}=1.04,95 \%$ CI 0.73, 1.46, $P=0.842)$ or unhealthy food branding (39.2 v. $37.7 \%$; adjusted $\mathrm{OR}=1.05,95 \% \mathrm{CI} 0.75,1.49, P=0.766)$.

\section{Brand attitudes}

Across conditions, children's perceptions of the unhealthy and healthier food sponsor products were generally

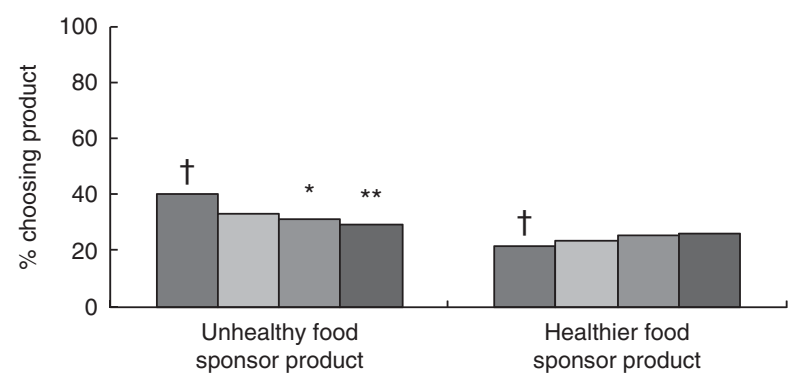

Fig. 3 Proportion choosing unhealthy food sponsor products and healthier food sponsor products, respectively, by sponsorship condition ( $\square$, non-food branding; $\square$, unhealthy food branding; $\square$, healthier food branding; $\square$, obesity prevention campaign branding) among students in grades 1 to 3 (aged $5-10$ years; $n$ 1124) from schools in metropolitan Melbourne, Australia, May-August 2016. ${ }^{\star} P<0.05$; ${ }^{* \star} P<0.01$; treference category for logistic regression analyses favourable (mean ratings $>3 \cdot 3$ ), except for ratings of the healthiness of the unhealthy food sponsor product (see Table 2). $\mathrm{H} 1_{\mathrm{c}}$ and $\mathrm{H} 2_{\mathrm{c}}$ were not supported. Compared with the non-food branding condition: children exposed to unhealthy food branding did not rate the unhealthy food sponsor product more favourably; children exposed to healthier food branding did not rate the healthier food sponsor product more favourably. There was no evidence that children exposed to obesity prevention campaign branding perceived the healthier food sponsor product as more favourable $\left(\mathrm{RQ} 1_{\mathrm{b}}\right)$ and the unhealthy food sponsor product as less favourable $\left(\mathrm{RQ} 1_{c}\right)$ than children exposed to non-food branding.

\section{Discussion}

The findings from this experiment suggest that brief exposure to branded sports merchandise can have some impact on young children's brand awareness and food product preferences. Specifically, we found that top-of-mind brand awareness of the healthier food sponsor product was significantly higher among children exposed to healthier food branding compared with non-food branding (21 v. 13\%). There was also evidence of reduced preference for the unhealthy food sponsor product among children exposed to the healthier food branding (31\%) or obesity prevention campaign branding (29\%) compared with children in the non-food branding condition (40\%), suggesting possible counter-advertising effects of healthier brands on unhealthy brands.

In experimental media research involving brief exposure to health-relevant communications it is typical for relatively small effect sizes to be found ${ }^{(49-51)}$, and this is true of the present study. The small, but significant effects found for impacts of the healthier sponsorship scenarios

Table 2 Ratings of the unhealthy food sponsor product and the healthier food sponsor product, by sponsorship condition, among students in grades 1 to 3 (aged 5-10 years; $n$ 1124) from schools in metropolitan Melbourne, Australia, May-August 2016

\begin{tabular}{|c|c|c|c|c|c|c|c|c|}
\hline & \multicolumn{8}{|c|}{ Sponsorship condition } \\
\hline & \multicolumn{2}{|c|}{$\begin{array}{c}\text { Non-food branding } \\
\text { (control) }\end{array}$} & \multicolumn{2}{|c|}{$\begin{array}{l}\text { Unhealthy food } \\
\text { branding }\end{array}$} & \multicolumn{2}{|c|}{$\begin{array}{l}\text { Healthier food } \\
\text { branding }\end{array}$} & \multicolumn{2}{|c|}{$\begin{array}{c}\text { Obesity prevention campaign } \\
\text { branding }\end{array}$} \\
\hline & Mean & SD & Mean & SD & Mean & SD & Mean & SD \\
\hline \multicolumn{9}{|l|}{ Unhealthy food sponsor product } \\
\hline Liking of product & 3.86 & 1.40 & 3.80 & 1.44 & 3.73 & 1.41 & 3.84 & 1.38 \\
\hline Product taste & 4.01 & $1 \cdot 31$ & 3.98 & 1.30 & 3.91 & 1.31 & 4.00 & 1.30 \\
\hline Healthiness of product & $2 \cdot 61$ & $1 \cdot 34$ & $2 \cdot 62$ & 1.36 & 2.59 & 1.35 & 2.56 & 1.34 \\
\hline Ask parents for product & 3.49 & 1.49 & 3.39 & 1.50 & 3.42 & 1.49 & 3.44 & 1.48 \\
\hline Feel if parents bought product & 3.90 & $1 \cdot 33$ & $3 \cdot 90$ & $1 \cdot 32$ & 3.74 & 1.33 & 3.85 & $1 \cdot 31$ \\
\hline \multicolumn{9}{|l|}{ Healthier food sponsor product } \\
\hline Liking of product & 3.57 & 1.45 & 3.58 & 1.48 & 3.48 & 1.54 & 3.50 & 1.52 \\
\hline Product taste & $3 \cdot 67$ & $1 \cdot 35$ & 3.69 & 1.36 & $3 \cdot 67$ & 1.38 & $3 \cdot 70$ & 1.44 \\
\hline Healthiness of product & 4.06 & 1.05 & $4 \cdot 12$ & 1.06 & 4.03 & 1.06 & 4.17 & 1.00 \\
\hline Ask parents for product & 3.43 & 1.48 & 3.42 & 1.48 & 3.42 & 1.46 & 3.41 & 1.50 \\
\hline Feel if parents bought product & 3.60 & $1 \cdot 38$ & 3.64 & 1.40 & 3.63 & 1.40 & 3.56 & 1.42 \\
\hline
\end{tabular}

No significant differences in mean ratings were found between the non-food branding condition and the unhealthy, healthier and obesity prevention campaign branding conditions, respectively (all $P>0.05$ ). 
on brand awareness and product preference could be substantially magnified if exposure to such pro-health sponsorship were to occur repeatedly. Furthermore, it is possible that some of our null findings (e.g. failure to find increased preference for healthier sponsor branded products following exposure to healthier sponsor branding) might manifest as real impacts if repeated exposure to such interventions could be achieved. Further research could test this proposition.

Contrary to our hypotheses, brief exposure to unhealthy food branding did not promote higher awareness of, or preference for, unhealthy food sponsor products. These null findings may be due to ceiling effects for unhealthy food brands that are already heavily marketed to children and already closely aligned with sport (i.e. Kellogg's NutriGrain, McDonald's and Gatorade), such that children had a strong prior 'dose' of advertising exposure that was not boosted by our brief intervention. Further research would be necessary to assess how exposure to sponsorship by less high-profile (or unknown) unhealthy food brands impacts children. Pre-testing children's awareness and attitudes to various unhealthy and healthy brands could help identify suitable products to test alongside one another.

Potential brand effects are important to account for when designing experiments of this nature. A limitation of the present study was that we only exposed participants to the sponsorship manipulation for one brand exemplar in a given product category. For example, all participants in the unhealthy food branding $\times$ breakfast cereal cell were shown a Nutri-Grain sponsored sports pack. Because the sponsorship manipulation was linked to particular brands, we cannot truly isolate the extent to which our results were driven by brand effects $v$. effects of the sponsorship manipulation, although having several product categories within a given sponsorship condition should have helped ameliorate any brand effects. A stronger design, which could be implemented in future research, would be to randomly assign participants sports merchandise for one of a number of potential brands within a given subcategory (e.g. Nutri-Grain or Milo cereal for the unhealthy food branding $\times$ breakfast cereal cell) and then offer these brands as potential choices in the subsequent food preference task, alongside their healthier counterparts (e.g. Weet-Bix and Cheerios). This would enable more rigorous assessment of how particular types of sponsorship affect participants' food preferences and evaluations than when the sponsorship manipulation is attached to specific food brands.

Children's attitudes towards the unhealthy and healthier food sponsor products were unaffected by the sponsorship intervention, suggesting that the small dose of exposure to the branded sports merchandise that students received was insufficient to shift attitudes. Future research could overcome this limitation by conducting a randomised controlled trial of longer duration in a more naturalistic sport setting that allows for cumulative exposure to various sponsorship scenarios, in the context of the other dynamics beyond mere brand exposure that are at play in junior sport (e.g. team bonding, emotion), which may be critical to how sponsorship operates. As well as assessing cumulative impacts on attitudes, such research could assess impacts on children's dietary behaviour. Conducting such a trial in actual junior sports settings would provide a more ecologically valid simulation of the sport sponsorship experience, whereby genuine participation in the sponsored activity may help build emotional bonding with the sponsor brand.

While this brief experiment did not find that simulated exposure to unhealthy food sponsorship of children's sport promoted unhealthy food preferences, we would urge caution in interpreting this result given other published literature on sponsorship effects. The most likely explanation for the present study's failure to find marked effects on this outcome is due to the intervention being of insufficient intensity to yield measurable effects on children and high levels of baseline exposure to advertising for the unhealthy foods. Further research assessing sponsorship effects using a randomised controlled trial design in junior sports settings is warranted. Prudently, we should act on the findings indicating that sponsorship by nonfood brands does not promote unhealthy food, that sponsorship by healthier food brands may promote healthier brands, and that sponsorship by healthier food brands and obesity prevention campaign brands may detract from the appeal of unhealthy food brands. Thus, encouraging junior sport sponsorship managers to contract these alternative types of brands as sponsors in place of unhealthy food brands could provide a feasible prohealth sponsorship alternative. Healthy sponsor criteria could be promoted and implemented in clubs to help them build healthier sponsorship arrangements and phase out unhealthy sponsors. Where an existing sponsor company owns multiple food brands, they could be encouraged to reorient their sponsorship arrangements towards promoting their healthier brands in place of their unhealthy brands (e.g. in Australia, Coca-Cola owns Mount Franklin bottled water which the company could promote through sport instead of regular Coca-Cola soft drink). Under these scenarios, unhealthy brands would receive less exposure, minimising potential harms to children's diets. Healthier brands and relevant non-food brands (e.g. sports apparel manufacturers) may have better perceived event-sponsor fit ${ }^{(52)}$ than unhealthy brands, which means that sport sponsorship could be an attractive promotional opportunity for these types of brands and would make replacement sponsorship more feasible.

It should be noted that our results revealed some effects of the sponsorship manipulation on awareness and preference for particular brands, but did not lead to a shift in the overall proportion of children choosing healthier food over unhealthier food. From a public health perspective, promoting healthier eating (irrespective of brand) is the 
ultimate goal, whereas from a commercial product marketing perspective promoting sales of particular brands is paramount. Given the large volume of promotions for unhealthy foods that children are exposed to regularly, it is unsurprising that this brief intervention was unable to elicit changes in more general food choice behaviours. The fact that it appears to have positively shifted children's healthier food awareness and product preferences at all demonstrates that replacement sponsorship by healthier food or non-food brands is a promising intervention. Further research employing a more intensive sponsorship intervention, random assignment of brands within sponsorship conditions and more comprehensive assessment of children's dietary behaviour post-intervention would improve our understanding of the extent to which various sponsorship scenarios impact the overall quality of children's diets. The application of methods that reduce the possibility of social desirability bias influencing responses (which may have occurred in the present study due to students being aware of their research participation and primed that it was about food products) is also needed to strengthen the evidence base regarding the potential benefits of pro-health sponsorship in junior sport settings.

\section{Conclusions}

The present study provided preliminary evidence suggesting that sponsoring children's sport with healthier food brands may promote greater awareness of these brands and prompt children to avoid unhealthy food brands. Establishing and implementing healthy sponsor criteria in sports clubs could forge healthier sponsorship arrangements and help phase out unhealthy food and beverage sponsors.

\section{Acknowledgements}

Acknowledgements: The authors are most grateful to the schools and students who participated in the study, and to Philippa Niven for her patience and rigour in preparing the visual stimuli for the study. Financial support: This work was supported by a Medical Research Grant from the Jack Brockhoff Foundation (grant number 4022) and by Cancer Council Victoria (where authors H.D., M.S. and M.W. are employees). The funders had no role in the design, analysis or writing of this article. Conflict of interest: All of the authors currently work for (or have previously worked for) organisations involved in public health research and advocacy. Authorship: H.D. designed the study, with input from all other authors. M.S. managed the data collection. H.D. and M.S. developed the study protocol and materials, analysed and interpreted the data, and drafted the manuscript, with critical input from all other authors. Etbics of buman subject participation: This study was conducted according to the guidelines laid down in the Declaration of Helsinki and all procedures involving human subjects were approved by the Cancer Council Victoria's Human Research Ethics Committee. Written informed consent was obtained from the parents/carers of all the child participants.

\section{References}

1. World Health Organization (2015) Global Strategy on Diet, Physical Activity, and Health: Childhood Overweight and Obesity. http://www.who.int/dietphysicalactivity/childhood/ en/ (accessed November 2016).

2. Australian Bureau of Statistics (2015) 4364.0.55.001 National Health Survey: First Results, 2014-15. Canberra: ABS.

3. Buttitta M, Iliescu C, Rousseau A et al. (2014) Quality of life in overweight and obese children and adolescents: a literature review. Qual Life Res 23, 1117-1139.

4. Singh AS, Mulder C, Twisk JWR et al. (2008) Tracking of childhood overweight into adulthood: a systematic review of the literature. Obes Rev 9, 474-488.

5. Reilly JJ \& Kelly J (2011) Long-term impact of overweight and obesity in childhood and adolescence on morbidity and premature mortality in adulthood: systematic review. Int $J$ Obes (Lond) 35, 891-898.

6. Cairns G, Angus K, Hastings G et al. (2013) Systematic reviews of the evidence on the nature, extent and effects of food marketing to children. A retrospective summary. Appetite 62, 209-215.

7. Chapman K, Kelly B \& King L (2009) Using a research framework to identify knowledge gaps in research on food marketing to children in Australia. Aust N Z J Public Health 33, 253-257.

8. Kelly B, Bauman AE \& Baur LA (2014) Population estimates of Australian children's exposure to food and beverage sponsorship of sports clubs. J Sci Med Sport 17, 394-398.

9. Strong WB, Malina RM, Blimkie CJ et al. (2005) Evidence based physical activity for school-age youth. J Pediatr $\mathbf{1 4 6}$, $732-737$.

10. Janssen I \& Leblanc AG (2010) Systematic review of the health benefits of physical activity and fitness in schoolaged children and youth. Int J Behav Nutr Phys Act 7, 40.

11. Australian Bureau of Statistics (2012) 4901.0 - Children's Participation in Cultural and Leisure Activities, Australia, April 2012. Canberra: ABS.

12. Kokko S, Donaldson A, Geidne S et al. (2016) Piecing the puzzle together: case studies of international research in health-promoting sports clubs. Glob Health Promot 23, 75-84.

13. World Cancer Research Fund International (2016) NOURISHING Framework. http://www.wcrf.org/int/policy/ nourishing-framework (accessed July 2016).

14. Kelly B, Baur LA, Bauman AE et al. (2011) Food and drink sponsorship of children's sport in Australia: who pays? Health Promot Int 26, 188-195.

15. Sherriff J, Griffiths D \& Daube M (2010) Cricket: notching up runs for food and alcohol companies? Aust $N$ Z J Public Health 34, 19-23.

16. Watson WL, Brunner R, Wellard L et al. (2016) Sponsorship of junior sport development programs in Australia. Aust NZ J Public Health 40, 326-328.

17. Macniven R, Kelly B \& King L (2015) Unhealthy product sponsorship of Australian national and state sports organisations. Health Promot J Aust 26, 52-56.

18. Carter MA, Signal L, Edwards R et al. (2013) Food, fizzy, and football: promoting unhealthy food and beverages through sport - a New Zealand case study. BMC Public Health 13, 126. 
19. Maher A, Wilson N, Signal L et al. (2006) Patterns of sports sponsorship by gambling, alcohol and food companies: an Internet survey. BMC Public Health 6, 95.

20. Grunert KG (1996) Automatic and strategic processes in advertising effects. J Mark 60, 88-101.

21. Cornwell TB, Weeks CS \& Roy DP (2005) Sponsorshiplinked marketing: opening the black box. $J$ Advert $\mathbf{3 4}$, 21-42.

22. Bennett R (1999) Sports sponsorship, spectator recall and false consensus. Eur J Mark 33, 291-313.

23. IMR Sports Marketing (2013) Australia/New Zealand Sponsorship Worth $\$ 880$ million. http://www.imrpublications. com/newsdetails.aspx?nid=44 (accessed October 2016).

24. Pettigrew S, Pescud M, Rosenberg M et al. (2012) Public support for restrictions on fast food company sponsorship of community events. Asia Pac J Clin Nutr 21, 609-617.

25. Morley B, Martin J, Niven P et al. (2012) Public opinion on food-related obesity prevention policy initiatives. Health Promot J Aust 23, 86-91.

26. Kelly B, Baur LA, Bauman AE et al. (2013) Views of children and parents on limiting unhealthy food, drink and alcohol sponsorship of elite and children's sports. Public Health Nutr 16, 130-135.

27. Kelly B, Baur LA, Bauman AE et al. (2012) Restricting unhealthy food sponsorship: attitudes of the sporting community. Health Policy 104, 288-295.

28. Walliser B (2003) An international review of sponsorship research: extension and update. Int J Advert 22, 5-40.

29. Smith G (2004) Brand Image transfer through sponsorship: a consumer learning perspective. J Mark Manage 20, 457-474.

30. Dean DH (1999) Brand endorsement, popularity, and event sponsorship as advertising cues affecting consumer pre-purchase attitudes. J Advert 28, 1-12.

31. Meenaghan T \& Shipley D (1999) Media effect in commercial sponsorship. Eur J Mark 33, 328-348.

32. Meenaghan T (2001) Understanding sponsorship effects. Psychol Mark 18, 95-122.

33. Kelly B, Baur LA, Bauman AE et al. (2011) Tobacco and alcohol sponsorship of sporting events provide insights about how food and beverage sponsorship may affect children's health. Health Promot J Aust 22, 91-96.

34. Brown K (2016) Association between alcohol sports sponsorship and consumption: a systematic review. Alcohol Alcohol 51, 747-755.

35. Pettigrew S, Rosenberg M, Ferguson R et al. (2013) Game on: do children absorb sports sponsorship messages? Public Health Nutr 16, 2197-2204.

36. Bestman A, Thomas SL, Randle M et al. (2015) Children's implicit recall of junk food, alcohol and gambling sponsorship in Australian sport. BMC Public Health 15, 1022.

37. Kelly B, Baur LA, Bauman AE et al. (2011) 'Food company sponsors are kind, generous and cool': (mis)conceptions of junior sports players. Int J Behav Nutr Phys Act 8, 95 .

38. Graff S, Kunkel D \& Mermin SE (2012) Government can regulate food advertising to children because cognitive research shows that it is inherently misleading. Health Aff (Millwood) 31, 392-398.

39. Moses LJ \& Baldwin DA (2005) What can the study of cognitive development reveal about children's ability to appreciate and cope with advertising? J Public Policy Mark 24, 186-201.

40. Wright P, Friestad M \& Boush DM (2005) The development of marketplace persuasion knowledge in children, adolescents, and young adults. J Public Policy Mark 24, 222-233.

41. Jones SC, Mannino N \& Green J (2010) 'Like me, want me, buy me, eat me': relationship-building marketing communications in children's magazines. Public Health Nutr 13, 2111-2118.

42. Kelly B, King L, Bauman AE et al. (2014) Identifying important and feasible policies and actions for health at community sports clubs: a consensus-generating approach. J Sci Med Sport 17, 61-66.

43. Australian Bureau of Statistics (2013) Technical Paper: Socio-Economic Indexes for Areas (SEIFA) 2011. ABS Catalogue no. 2033.0.55.001. Canberra: ABS.

44. McAlister AR \& Cornwell TB (2012) Collectible toys as marketing tools: understanding preschool children's responses to foods paired with premiums. J Public Policy Mark 31, 195-205.

45. Levin AM \& Levin IP (2010) Packaging of healthy and unhealthy food products for children and parents: the relative influence of licensed characters and brand names. J Consum Behav 9, 393-402.

46. Dixon H, Scully M, Niven P et al. (2014) Effects of nutrient content claims, sports celebrity endorsements and premium offers on pre-adolescent children's food preferences: experimental research. Pediatr Obes 9, e47-e57.

47. Jalleh G, Donovan RJ, Giles-Corti B et al. (2002) Sponsorship: impact on brand awareness and brand attitudes. Soc Mark Q 8, 35-45.

48. Dixon H, Scully M, Kelly B et al. (2014) Can counteradvertising reduce pre-adolescent children's susceptibility to front-of-package promotions on unhealthy foods? Experimental research. Soc Sci Med 116, 211-219.

49. Anderson CA \& Bushman BJ (2002) Psychology. The effects of media violence on society. Science 295, 2377-2379.

50. Groesz LM, Levine MP \& Murnen SK (2002) The effect of experimental presentation of thin media images on body satisfaction: a meta-analytic review. Int J Eat Disord 31, 1-16.

51. Dixon HG \& Sargent JD (2008) The role of entertainment media in promoting or discouraging tobacco use. In The Role of the Media in Promoting and Reducing Tobacco Use, pp. 357-428 [RM Davis, EA Gilpin, B Loken et al., editors]. Bethesda, MD: US Department of Health and Human Services, National Institutes of Health, National Cancer Institute.

52. Gwinner KP, Larson BV \& Swanson SR (2009) Image transfer in corporate event sponsorship: assessing the impact of team identification and event-sponsor fit. Int J Manage Mark Res 2, 1-15. 